\title{
MODELLING OF THE WORKING PROCESS OF VIBRATORY CONVEYORS APPLIED IN THE METALLURGICAL INDUSTRY
}

\begin{abstract}
The suitability of the currently used vibratory transport models for the case of applying the vibratory conveyors in the metallurgical industry, was analysed in the hereby paper. It was found that these models, due to not taking into account an influence of the air flow through the feed layer, do not usually correspond with conditions occurring in this industry. The analysis of the productivity of vibratory conveyors applied in the metallurgical industry should include an influence of dusty and powdery fractions present in transported materials, since the air flow resistance can cause-in such cases-a significant decrease of the transport velocity. The mathematical and simulation model of the feed, taking into account the influence of the air flowing through the feed, was formulated in the study. Its compatibility with experimental investigations was also pointed out.

Keywords: vibratory conveyors, feed models, transport velocity, air flow resistance
\end{abstract}

\section{Introduction}

The characteristic feature differentiating vibratory conveyors from other machines for loose materials handling is the fact that the transported material is moving due to small progressive vibrations of the trough, in the direction inclined versus the force of gravity [1-4]-Fig. 1. Thus, these conveyors neither have elements transporting feed along the through nor require a trough elasticity, since the source of the feed transportation is its stroke motion forced by vibrations of a trough. On account of this, vibratory conveyors have several good points in applications of transporting raw materials and products at short distances in the metallurgical industry.

Such conveyors enable transportation of:

a) hot materials, even up to $1000^{\circ} \mathrm{C}$,

b) caustic materials, depending on the applied lining,

c) materials emitting toxic fumes and dusts (for troughs of closed cross-sections),

d) materials causing fire or explosion hazards.

They also allow:

e) receiving and utilising the transported material heat, e.g. for warming furnace blowing [5],

f) performing (during transporting) drying or wetting processes, chemical reactions and other, such as e.g. introduction of the needed orientation of feed particles, etc.

They also display several functional features essential in the metallurgical industry:

g) they are highly reliable and resistant when operating in a dusted and contaminated environment, h) accidental contact with them during operations is usually not dangerous for the service men.

These features cause a high suitability of vibratory conveyors for the short distance transportation of loose materials, such as: hot furnace slag, dusts from dedusting devices, ground ceramic materials, powders (e.g. aluminium), etc. [5,6].

\section{Formulation of the problem and the aim of the study}

Specificity of the metallurgical industry, contrary to other applications of the vibratory transport, is based on the feed grain size composition, containing usually a lot of dusty and powdery materials, of an average grain diameter being below $0.5 \mathrm{~mm}$. Such materials, due to a difficult air flow during their vertical movement, are moving along the trough with much lower transporting velocity (even 5-times lower than coarse-grained materials [7]).

However, these factors are not represented in the feed models currently used for the selection of conveyors. The presently applied feed models: point-based (,flat particle”) [1,8], combined rheological models [9] and the newest simulation models of the DEM type (Discrete Element Method) $[10,11]$ do not allow to take into account the air influence. In a similar fashion, models in which air resistances were considered but related only to the movement of an individual particle or layer [12], do not solve the problem. In case of a feed of a typical thickness (being multiple of grain diameters), the grains movement and air resistances

\footnotetext{
* AGH, UNIVERSITY OF SCIENCE AND TECHNOLOGY, FACULTY OF MECHANICAL ENGINEERING AND ROBOTICS, AL. A. MICKIEWICZA 30, 30-059 KRAKOW, POLAND

\# Corresponding author: lukaszb@agh.edu.pl
} 
a)

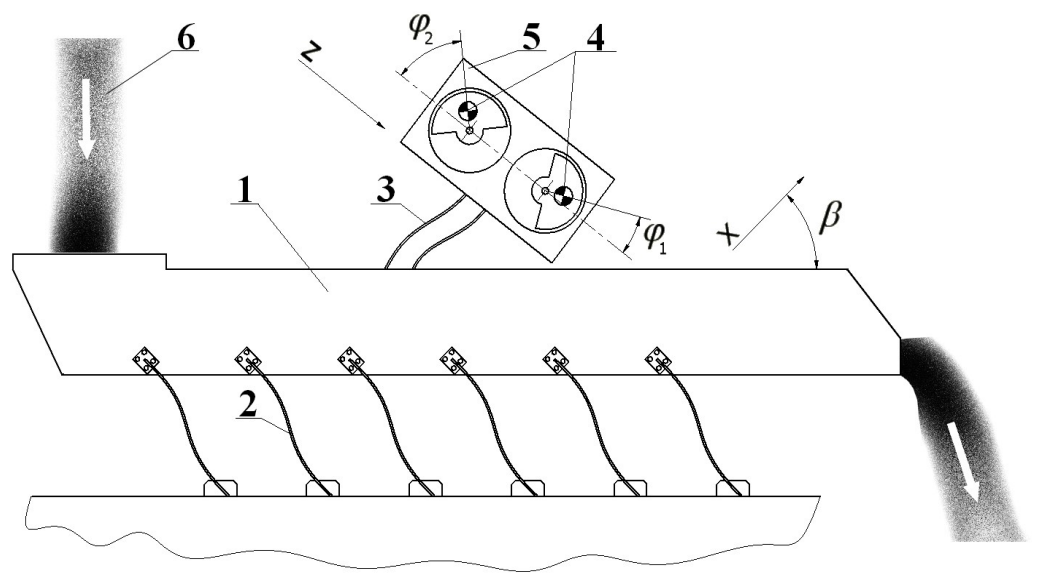

b)

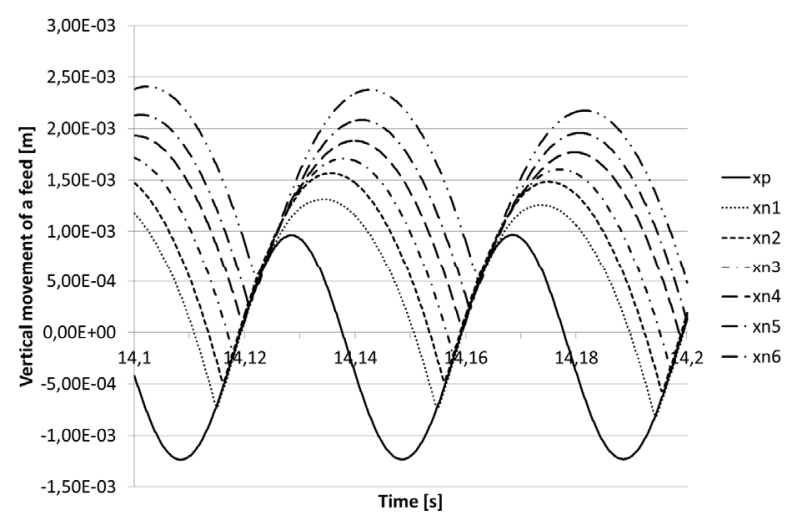

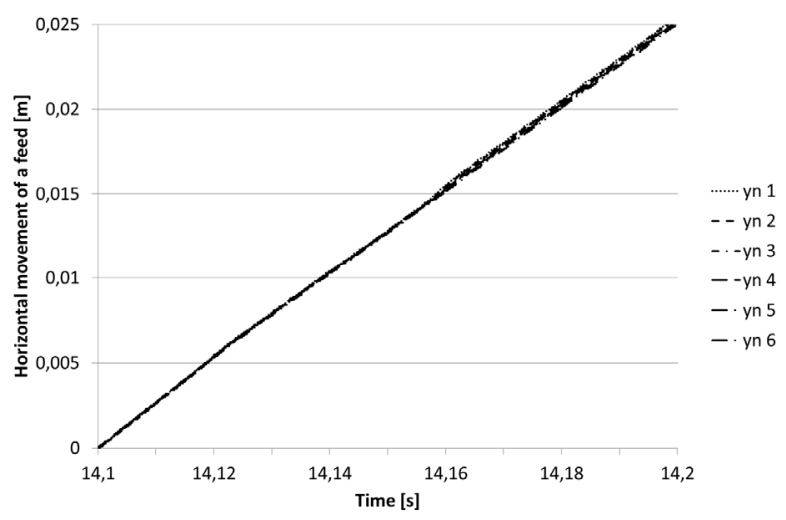

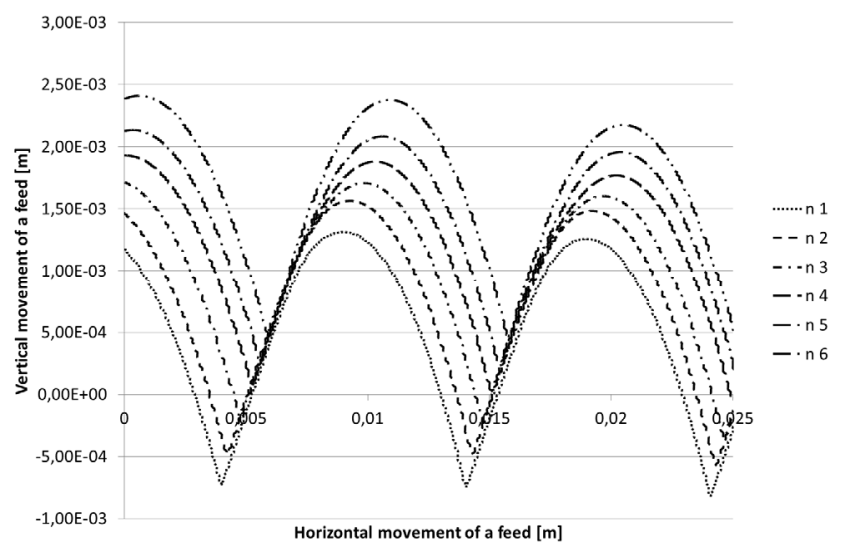

Fig. 1. a) Schematic presentation of the structure of the typical vibratory conveyor: 1 - trough, 2 - main springs (leaf springs), 3 - supporting springs of vibrators, 4 - unbalanced masses, 5 - vibrators system body, 6 - transported material (feed).

b) Waveforms of up-and-down and translatory motions of a trough $-x_{p}(t), y_{p}(t)$ and feed layers $-x_{n i}(t), y_{n i}(t), i=1 . .6$ as a function of time $t$, and vertical movement $y_{p}$ versus horizontal movement $x_{n} ; y_{n}\left(x_{n}\right)$

depend on the place taken by the particle in the layer and on the feed layer thickness.

The purpose of this study is to formulate the model of the vibratory transport process, suitable for investigations of efficiency and running of transient processes of machines applied under conditions of the metallurgical industry. The model should be especially suitable in testing the feed of a large dusty fractiontypical for this industry-for which the recently used models are disappointing. Due to a high accuracy of numerical simulation models and the possibility of investigating, by means of them, the steady as well as transient states (start-up, transient resonance
$[13,14])$ and an influence of the feed on the conveyor running, the analysis will be carried out for the multilayered numerical feed models, developed by the authors $[8,13]$.

\section{Model of the vibratory conveyor with the feed layered description}

The simulation model of the system: conveyor-loose feed, shown in Fig. 2, was proposed and verified in the quoted earlier papers of the authors. 


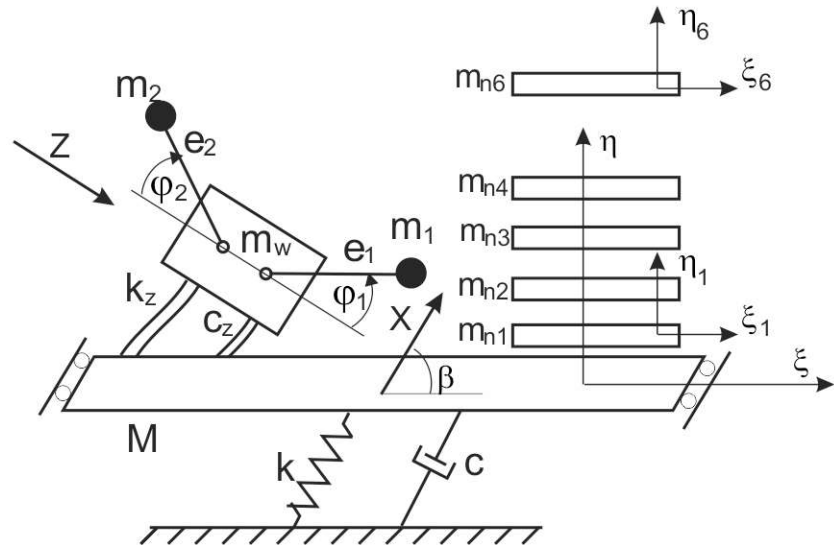

Fig. 2. Basic model of the conveyor with the feed layered model

where:

$x$ - direction of the conveyor working motion,

$z$ - direction of the conveyor motion,

$M$ - conveyor body mass,

$k, c-$ stiffness and damping of the conveyor suspension in the working direction, respectively,

$m_{w}-$ ibrator body mass,

$m_{1}, m_{2}$ - vibrating unbalanced masses,

$e_{1}, e_{2}-$ eccentric of unbalanced masses,

$J_{w}-$ moment of inertia of rotational parts of the vibrator,

$J_{s 1}, J_{s 2}-$ moment of inertia of rotational parts of the motor,

$M_{e l}$ - electric moment of the motor,

$\beta-$ inclination angle of vibrations,

$k_{z}, c_{z}-$ stiffness and damping of the vibrator, respectively,

$m_{n i}-$ masses of individual feed layers,

$\eta$ - vertical coordinate of the feed motion (perpendicular to the conveyor trough),

$\xi$ - horizontal coordinate of the feed motion (tangent to the conveyor trough).

The following equations of motion describe the above model:

$\ddot{x}\left(M+m_{w}+m_{1}+m_{2}\right)+\ddot{\varphi}_{1} \cdot m_{1} \cdot e_{1} \cdot \cos \left(\varphi_{1}\right)+$

$+\ddot{\varphi}_{2} \cdot m_{2} \cdot e_{2} \cdot \cos \left(\varphi_{2}\right)=-k x-c \dot{x}+\dot{\varphi}_{1}^{2} m_{1} e_{1} \sin \left(\varphi_{1}\right)+$

$+\dot{\varphi}_{2}^{2} m_{2} e_{2} \sin \left(\varphi_{2}\right)-F_{10} \sin (\beta)-T_{10} \cos (\beta)$

$\ddot{z}\left(m_{w}+m_{1}+m_{2}\right)+\ddot{\varphi}_{1}\left(-m_{1} e_{1} \sin \varphi_{1}\right)+\ddot{\varphi}_{2}\left(m_{2} e_{2} \sin \varphi_{2}\right)=$

$=-k z-c \dot{z}+\dot{\varphi}_{1}^{2} m_{1} e_{1} \cos \left(\varphi_{1}\right)-\dot{\varphi}_{2}^{2} m_{2} e_{2} \cos \left(\varphi_{2}\right)$

$\ddot{\varphi}_{1}\left(J_{w}+m_{1} e_{1}^{2}+J_{s_{1}}\right)+\ddot{x}\left(m_{1} e_{1} \cos \varphi_{1}\right)+\ddot{z}\left(-m_{1} e_{1} \sin \varphi_{1}\right)=M_{e l_{1}}$

$\ddot{\varphi}_{2}\left(J_{w}+m_{2} e_{2}^{2}+J_{S_{2}}\right)+\ddot{x}\left(m_{2} e_{2} \cos \varphi_{2}\right)+\ddot{z}\left(-m_{2} e_{2} \sin \varphi_{2}\right)=M_{e l 2}$

$m_{n 1} \ddot{\xi}_{1}=T_{10}-T_{21}$

$m_{n 1} \ddot{\eta}_{1}=-m_{n 1} g+F_{10}-F_{21}$

$m_{n 2} \ddot{\xi}_{2}=T_{21}-T_{32}$

$m_{n 2} \ddot{\eta}_{2}=-m_{n 2} g+F_{21}-F_{32}$

$m_{n 3} \ddot{\xi}_{3}=T_{32}-T_{43}$

$m_{n 3} \ddot{\eta}_{3}=-m_{n 3} g+F_{32}-F_{43}$

$m_{n 4} \ddot{\xi}_{4}=T_{43}$ $m_{n 4} \ddot{\eta}_{4}=-m_{n 4} g+F_{43}$

$\cdots$

$m_{n j} \ddot{\xi}_{j}=T_{j, j-1}$

$m_{n j} \ddot{\eta}_{j}=-m_{n j} g+F_{j, j-1}$

$\xi_{0}=x \cos \beta \quad \eta_{0}=x \sin \beta$

if $\eta_{1} \geq \eta_{0} \quad F_{10}=0 \quad$ else

$F_{10}=\left(\eta_{0}-\eta_{1}\right)^{p} \cdot k \cdot\left\{1-\frac{1-R^{2}}{2}\left[\begin{array}{l}1-\operatorname{sgn}\left(\eta_{0}-\eta_{1}\right) \cdot \\ \operatorname{sgn}\left(\dot{\eta}_{0}-\dot{\eta}_{1}\right)\end{array}\right]\right\}$

$T_{10}=-\mu F_{10} \operatorname{sgn}\left(\dot{\xi}_{1}-\dot{\xi}_{0}\right)$

if $\eta_{2} \geq \eta_{1} \quad F_{21}=0 \quad$ else

$F_{21}=\left(\eta_{1}-\eta_{2}\right)^{p} \cdot k \cdot\left\{1-\frac{1-R^{2}}{2}\left[\begin{array}{l}1-\operatorname{sgn}\left(\eta_{1}-\eta_{2}\right) \cdot \\ \operatorname{sgn}\left(\dot{\eta}_{1}-\dot{\eta}_{2}\right)\end{array}\right]\right\}$

$T_{21}=-\mu F_{21} \operatorname{sgn}\left(\dot{\xi}_{2}-\dot{\xi}_{1}\right)$

if $\eta_{3} \geq \eta_{2} \quad F_{32}=0 \quad$ else

$F_{32}=\left(\eta_{2}-\eta_{3}\right)^{p} \cdot k \cdot\left\{1-\frac{1-R^{2}}{2}\left[\begin{array}{l}1-\operatorname{sgn}\left(\eta_{2}-\eta_{3}\right) \cdot \\ \operatorname{sgn}\left(\dot{\eta}_{2}-\dot{\eta}_{3}\right)\end{array}\right]\right\}$

$T_{32}=-\mu F_{32} \operatorname{sgn}\left(\dot{\xi}_{3}-\dot{\xi}_{2}\right)$

if $\eta_{4} \geq \eta_{3} \quad F_{43}=0 \quad$ else

$F_{43}=\left(\eta_{3}-\eta_{4}\right)^{p} \cdot k \cdot\left\{1-\frac{1-R^{2}}{2}\left[\begin{array}{l}1-\operatorname{sgn}\left(\eta_{3}-\eta_{4}\right) \cdot \\ \operatorname{sgn}\left(\dot{\eta}_{3}-\dot{\eta}_{4}\right)\end{array}\right]\right\}$

$T_{43}=-\mu F_{43} \operatorname{sgn}\left(\dot{\xi}_{4}-\dot{\xi}_{3}\right)$

$\cdots$

if $\eta_{j} \geq \eta_{j-1} F_{j, j-1}=0$ else

$F_{j, j-1}=\left(\eta_{j-1}-\eta_{j}\right)^{p} \cdot k \cdot\left\{1-\frac{1-R^{2}}{2}\left[\begin{array}{c}1-\operatorname{sgn}\left(\eta_{j-1}-\eta_{j}\right) \cdot \\ \operatorname{sgn}\left(\dot{\eta}_{j-1}-\dot{\eta}_{j}\right)\end{array}\right]\right\}$

$T_{j, j-1}=-\mu F_{j, j-1} \operatorname{sgn}\left(\dot{\xi}_{j}-\dot{\xi}_{j-1}\right)$

\section{Decrease of the transport velocity related to the increase of the feed layer thickness}

Experiments indicate [7], that e.g. the transport velocity of a river sand should be decreasing by app. $1 \%$ for each additional centimetre of a feed, for a feed layer thickness up to $0.2 \mathrm{~m}$.

Simulation investigations (Fig. 3) based on the presented feed layered model, not taking into account air flow resistances, reflect the decrease of the feed transport velocity with the increase of the feed layer thickness. This decrease is in agreement with the observation when the feed layer thickness is larger than $8 \mathrm{~cm}$. For smaller feed layer thicknesses this decrease is smaller, while for layers of a thickness below $3 \mathrm{~cm}$ and the coefficient of throw value above 2.25 , numerical simulations indicate a narrow range in which an increase of the layer thickness causes a small increase of the transport velocity. This effect was not described, thus far, in references. 


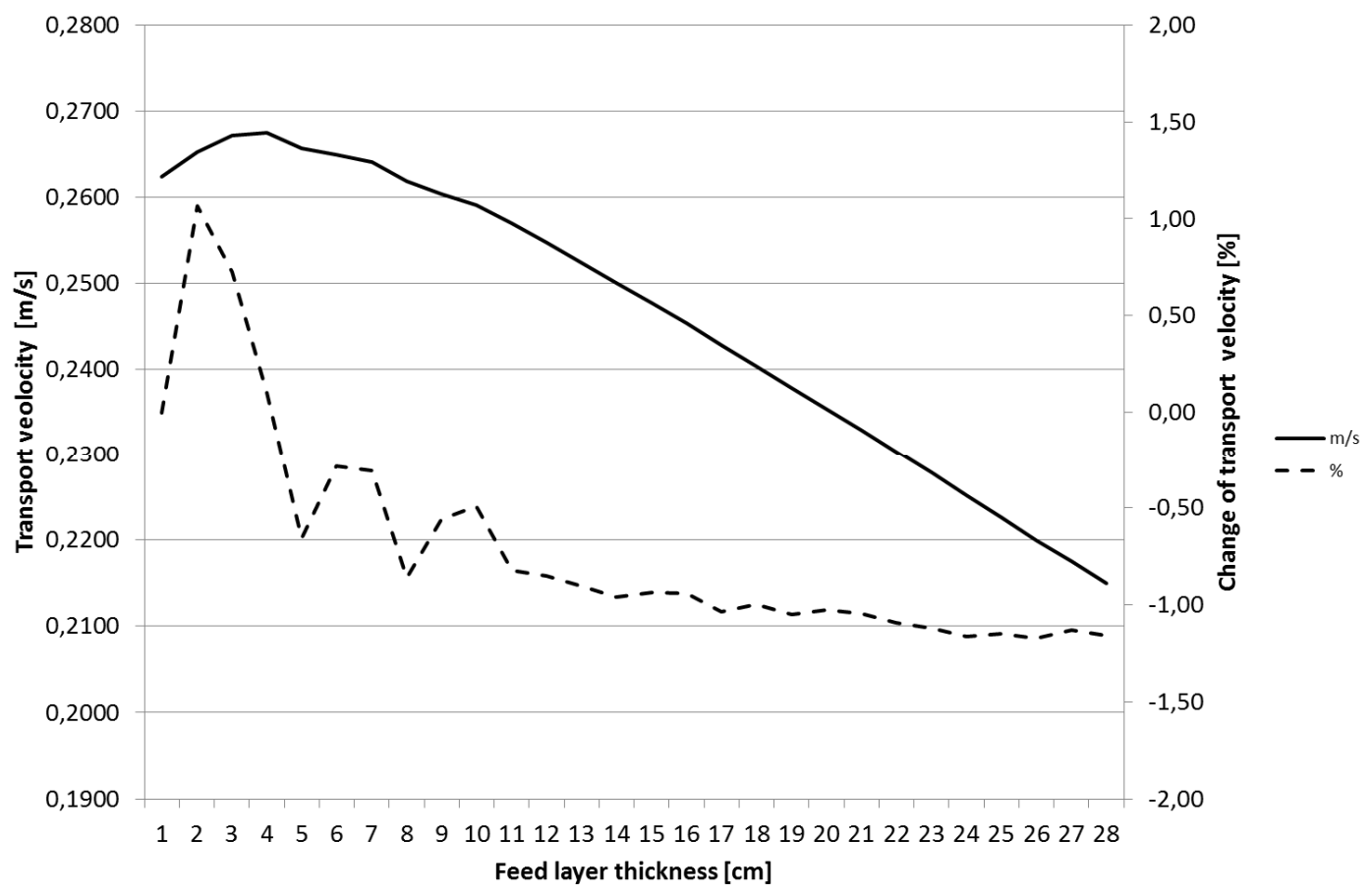

Fig. 3. Influence of the feed layer thickness on the transport velocity: absolute value (upper diagram) and percentage change of this velocity (lower diagram)

\section{Air flow through the feed}

In case of dusty materials a significant [7]-even a multipledecrease of the transport velocity within a wide range of layer thicknesses was observed. The main reason of the decrease of the feed transport velocity with the feed thickness increase constitutes a more difficult air flow through the transported material. This hindered air flow, for larger feed layer thicknesses, causes the air cushion formation between the feed and conveyor trough and-in consequence-slowing down or even stoppage of the transportation.

To take into account this effect, the feed layered model was supplemented by the model of air influencing individual feed layers. It was assumed, that the air flow causes formation of damping forces proportional to the air flow rate through the feed layer.

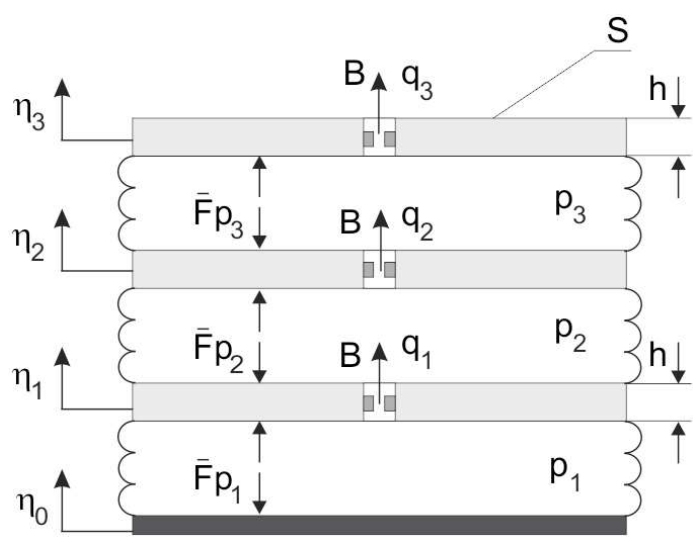

Fig. 4. Model of the air flow through the feed layers (seen in this Figure for the first three layers) where:

$q_{1}, q_{2}, q_{3}-$ air flow rates between layers $\left[\mathrm{m}^{3} / \mathrm{s}\right]$

$p_{1}, p_{2}, p_{3}-$ air pressure in between layers $\left[\mathrm{N} / \mathrm{m}^{2}\right]$,

$h$ - feed layer thickness [m],

$S$ - feed surface area $\left[\mathrm{m}^{2}\right]$,

$B$ - damping coefficient of the air flow through the feed layer $\left[\mathrm{Ns} / \mathrm{m}^{5}\right]$,

$F p_{1}, F p_{2}, F p_{3}$ - forces originated from the air pressure influencing individual feed layers.

The calculation process of forces influencing individual feed layers is described below.

As the first step, values of the air flow rates through individual feed layers are determined. Knowing velocities of individual feed layers the following is obtained:

$$
\begin{aligned}
& q_{1}=\left(\dot{\eta}_{0}-\dot{\eta}_{1}\right) \cdot S \\
& q_{2}=q_{1}+\left(\dot{\eta}_{1}-\dot{\eta}_{2}\right) \cdot S \\
& q_{3}=q_{2}+\left(\dot{\eta}_{2}-\dot{\eta}_{3}\right) \cdot S \\
& q_{4}=q_{3}+\left(\dot{\eta}_{3}-\dot{\eta}_{4}\right) \cdot S \\
& q_{5}=q_{4}+\left(\dot{\eta}_{4}-\dot{\eta}_{5}\right) \cdot S \\
& q_{6}=q_{5}+\left(\dot{\eta}_{5}-\dot{\eta}_{6}\right) \cdot S
\end{aligned}
$$

The next step is the calculation of the air pressure in between individual feed layers:

$$
\begin{aligned}
& p_{6}=q_{6} \cdot B \cdot h \\
& p_{5}=p_{6}+q_{5} \cdot B \cdot h \\
& p_{4}=p_{5}+q_{4} \cdot B \cdot h \\
& p_{3}=p_{4}+q_{3} \cdot B \cdot h \\
& p_{2}=p_{3}+q_{2} \cdot B \cdot h \\
& p_{1}=p_{2}+q 1 \cdot B \cdot h
\end{aligned}
$$


Knowing pressures it is possible to calculate the air pressure forces in between layers:

$$
\begin{aligned}
& F p_{1}=p_{1} \cdot S \\
& F p_{2}=p_{2} \cdot S \\
& F p_{3}=p_{3} \cdot S \\
& F p_{4}=p_{4} \cdot S \\
& F p_{5}=p_{5} \cdot S \\
& F p_{6}=p_{6} \cdot S
\end{aligned}
$$

\section{Simulation investigations}

The feed layered model in the form of the set of equations (2) and the mathematical model of trough vibrations (1) were supplemented with influences related to the air flow through the feed layers (5). The series of more than 4000 simulations of the conveyor working process were performed for the model changed in such way.

\section{Transport velocity}

The basic parameter, which should be properly reflected by the feed model, is the average transport velocity $v$ as well as its change in dependence on the feed amount and kind. This velocity can be determined from the modified semi-empirical W.A Bauman formula, which takes into account the coefficient of throw and the trough inclination angle (in the investigated case the trough is horizontal and thus the inclination angle equals zero).

$$
v=(a-b \sin \alpha) A \omega \cos \beta \sqrt{1-\frac{1}{k_{p}^{2}}}
$$

where: $a, b$-experimental coefficients, $k_{p}$-coefficient of throw, $\alpha$ - lead angle of the trough, $\beta$-inclination angle of the direction of vibrations to the trough plane, $A, \omega$ - amplitude and angular velocity of vibrations, respectively.

For the steady coefficient of throw $k_{p}$, factor $A \omega$ can be determined from the equation:

$$
A \omega=\frac{k_{p} g \cos \alpha}{\omega \sin \beta}
$$

Parameters occurring in the equation, for the tested conveyor and river sand as the feed material, have the following values: lead angle of the trough $\alpha=0$ degree, inclination angle of the direction of vibrations $\beta-30$ degrees, experimental coefficient $a$ for powdery-grainy material - from 0.4 to 0.8 - was assumed: $a=0.6$ (Plavinskij, 1969). The analysis was performed for two coefficients of throw: $k_{p}=2.17$ (single-trough conveyor of a heavy type), and $k_{p}=2.79$ (single-trough conveyor of a light type), both of inertial drives (Plavn).

For such parameters average transport velocities are equal: $v_{2,17}=0.13 \mathrm{~m} / \mathrm{s}, v_{2,79}=0.18 \mathrm{~m} / \mathrm{s}$.

\section{Transport velocity - simulation investigations without taking into account the air resistance}

The feed layered model was investigated with regard to its ability of the proper determination of the feed transport velocity. This model was tested for a wide variability range of coefficients of throw (from 1.53 to 4.03 ) as well as for a large variability of the feed layer thicknesses (from 2 to $29 \mathrm{~cm}$ ). The results of the performed simulations are shown in Fig. 5. The zone coresponding to the range of parameters applied usually at building industrial vibratory conveyors are marked by a frame in the diagram.

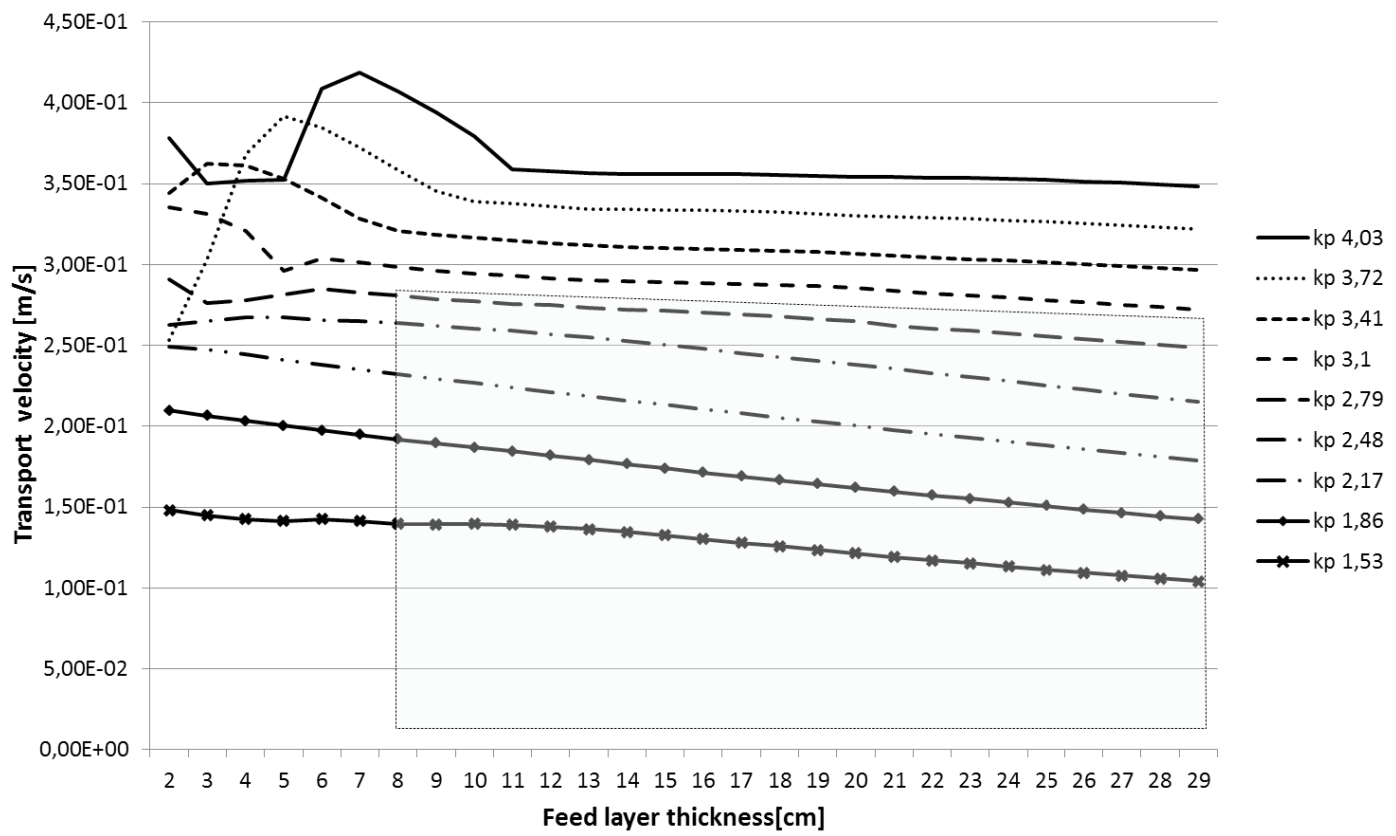

Fig. 5. Changes of the transport velocity in dependence of the thickness of the feed layer for various coefficients of throw. The range of the variability of parameters used usually in industrial vibratory conveyors is marked by a frame (feed layer thickness: $8-30 \mathrm{~cm}$, coefficient of throw: 1.5-3.3) 
As can be seen, the feed layered model differenciates the feed transport velocity with changes of the coefficient of throw as well as with changes of the thickness of the transported feed layer.

The transport velocity obtained from the numerical calculations, for two coefficients of throw (2.17 and 2.79) were compared with the results from the experimental W.A. Bauman formula. Since the experimental equation does not take into account the feed layer thickness for which the transport velocity is calculated, it was assumed that this value corresponds to the feed layer of a thickness of $20 \mathrm{~cm}$. It results from this comparison (Fig. 6), that velocities obtained from the feed layered model not taking into account air resistances are approximately $50 \%$ higher than the ones obtained by means of the modified (Plavn) semi-empirical W.A Bauman formula. This difference can not be explained by means of parameters contained in the layered model.

\section{Transport velocity-simulation investigations of the feed layered model with taking into account the air flow resistance}

The feed layered model, taking into account the air flow resistance, was investigated with regard to its ability of the proper determination of the feed transport velocity. This model was tested for the wide variability of coefficients of throw and the feed layer thicknesses. The influence of the damping coefficient $B$ of the air flow through the layer (in the variability range from 0 to $12000\left[\mathrm{Ns} / \mathrm{m}^{5}\right]$ ) was tested. The results of the performed simulations for $B=3000\left[\mathrm{Ns} / \mathrm{m}^{5}\right]$ (as an example) are presented in Fig. 7. The zone determined by parameters applied in building industrial vibratory conveyors is marked in the diagram.

\section{All curves were determined for the coefficient of the air flow resistance $\boldsymbol{B}=\mathbf{3 0 0 0}\left[\mathrm{Ns} / \mathrm{m}^{5}\right]$}

When these curves are compared with the transport velocity curves for the model not taking into account the air flow resistance (Fig. 5) a significant lowering and smoothing of curves is seen in the whole variability range of parameters.

\section{Determination of the coefficient of the air flow resist- ance for a river sand}

Resistance values of the air flow through the feed layer significantly influences the feed transport velocity. By comparing the transport velocities obtained from the feed layered model, taking into account resistances of the air flow, with velocities obtained from the experimental W.A Bauman formula it is possible to determine the air flow resistances for the selected feed-river sand.

Transport velocities for two, assumed previously, coefficients of throw were compared. The results are given in Fig. 8.

Values of the coefficient of air flow resistance for both coefficients of throw, assuring the expected transport velocity, were read from diagrams (by interpolation). These values are equal: $B=7500\left[\mathrm{Ns} / \mathrm{m}^{5}\right]$ for $k_{p}=2.79$ and $B=7000\left[\mathrm{Ns} / \mathrm{m}^{5}\right]$ for $k_{p}=2.17$.

Differences in values of the read coefficient $B$ can be explained by the accuracy of the calculated velocity. It should be remembered that the coefficient ' $a$ ' in the W.A Bauman formula has not a constant value but is given as an interval of values and in the investigated case can be changing within limits: from 0.4 to 0.8 . On the other hand, for the needs of the coefficient

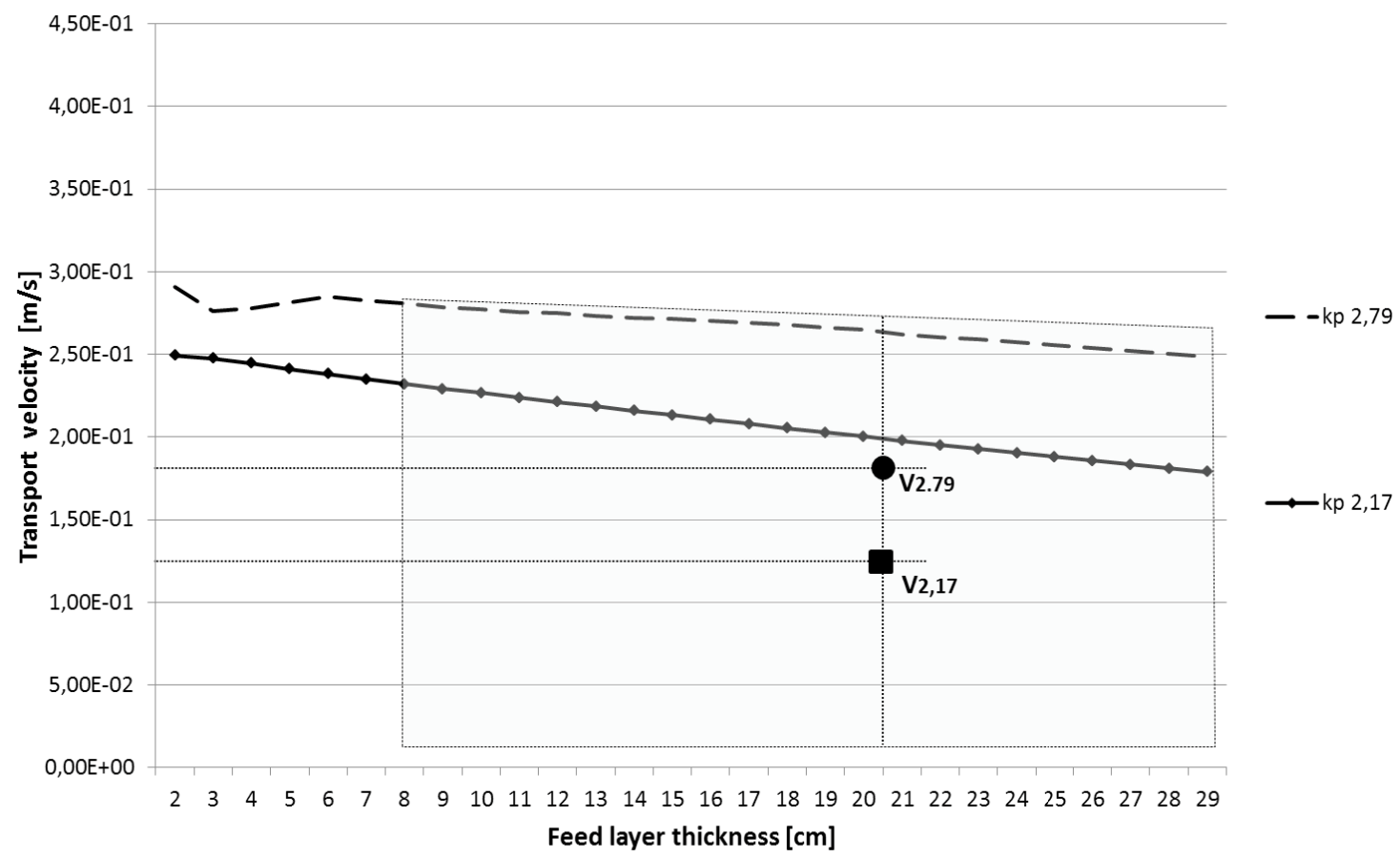

Fig. 6. Transport velocities obtained by means of the semi-empirical method (a circle and square in the diagram) for two selected coefficients of throw in relation to velocities obtained from numerical calculations without taking into account the air flow resistance 


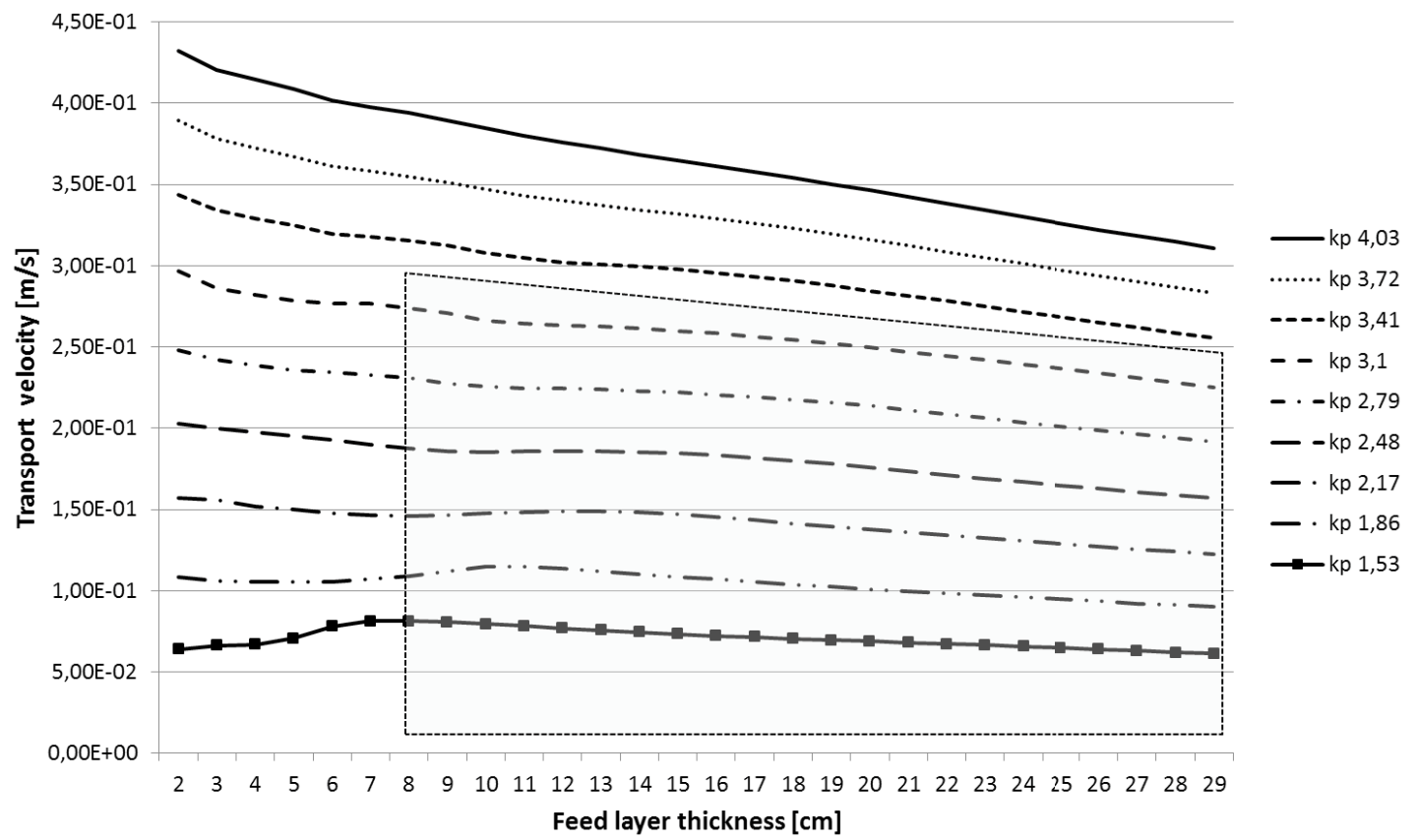

Fig. 7. Changes of the transport velocity in dependence of the thickness of the feed layer for various coefficients of throw. The range of the variability of parameters usually used in industrial vibratory conveyors is marked by a frame (feed layer thickness: $8-30 \mathrm{~cm}$, coefficient of throw: 1.5-3.3)

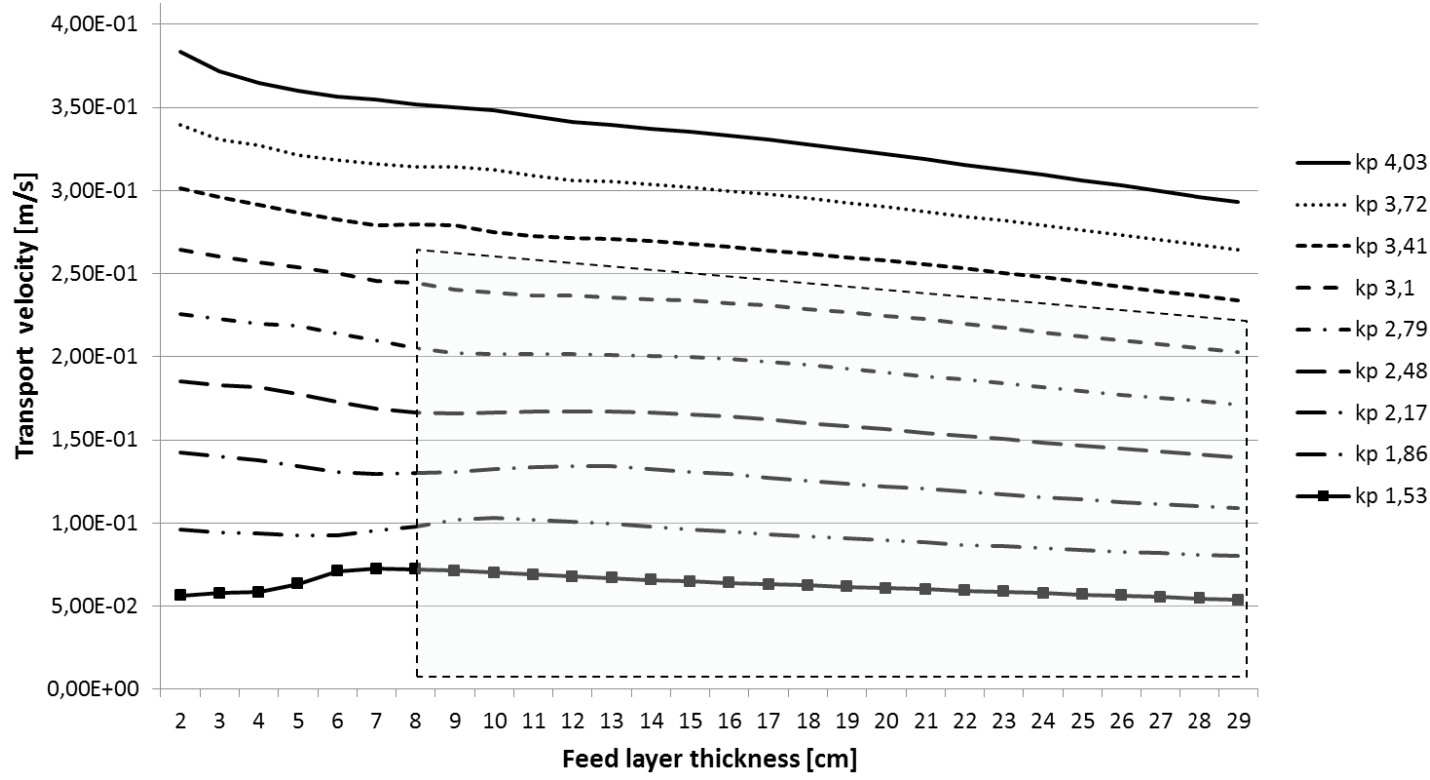

Fig. 8. Transport velocity of the river sand on the vibratory conveyor in dependence of the feed layerthickness for various coefficients of throw. The variability range of parameters in industrial vibratory conveyors is marked by a frame in the diagram (feed thickness: $8-30 \mathrm{~cm}$, coefficient of throw: 1.5-3.3)

$B$ determination, the expected velocity was calculated for the arbitrarily stabilised coefficient $a=0.6$.

Averaging both read values the coefficient of air resistance for the river sand equal $B=7250\left[\mathrm{Ns} / \mathrm{m}^{5}\right]$ was obtained.

When the coefficient of the resistance of the air flow through the feed layer is determined, the feed layered model, taking into account the air flow resistance, allows to determine the transport velocity for the whole variability range of the coefficients of throw as well as of the feed layer thicknesses (Fig. 8).

All curves were determined for the coefficient of air flow resistance $\boldsymbol{B}=7250\left[\mathrm{Ns} / \mathrm{m}^{5}\right]$.

\section{Conclusions}

The feed layered model taking into account resistances of the air flow through the feed layers is presented in the study.

1. This model allows to determine, by means of simulations, transport velocities of dusty and powdery materials, being in aggreement with the experimental results.

2. For the coefficient of throw of the range from 1.5 to 3.1 and the feed layer thickness from 5 to $30 \mathrm{~cm}$ the essential decrease of the transport velocity is observed with the increase of the air flow resistance, while for large values of $B$ 
constant (of the order: 24000) a gradual decay of a transport occurs.

3. For the coefficients of throw above 3.1 and low coefficients of the air flow resistance $\left(B<3000\left[\mathrm{Ns} / \mathrm{m}^{5}\right]\right)$ certain zones of the transport velocity increase are seen, which is related to restoring the feed 'single-tact' motion. At higher resistances of the air flow the transport velocity decreases again.

4. On the bases of comparisons of experimental data with numerical calculations results the coefficient of the resistance of air flow through the feed layer was determined. This coefficient for the river sand equals approximately $B=7250\left[\mathrm{Ns} / \mathrm{m}^{5}\right]$. This value should be treated as an approximate one, due to not accurate conditions of investigations.

\section{REFERENCES}

[1] I.I. Blekhman, Vibrational Mechanics, World Scientific, Singapore-New Jersey-London 2000.

[2] A. Rovetta, Machine Vibration 1 (1992).

[3] I.F. Goncharevich, K.V. Frolov, E.I. Rivin, Theory of Vibratory Technology, Hemisphere Publ. Corp. N.York, Washington, London 1990.
[4] M. Goździecki, H. Świątkiewicz, Przenośniki (in Polish), WNT, Warszawa 1975.

[5] J. Giergiel, J. Liszka, III Sympozjum Techniki Wibracyjnej, Wyd. AGH Kraków (1973).

[6] J. Michalczyk, Analiza wpływu drgań związanych z pracą przenośnika wibracyjnego na pękanie płaszcza wodnego komory do wytwarzania proszku aluminium, Report for Zakłady Metalurgiczne Skawina, AGH, Kraków (1986).

[7] V. Plavinskij and others, Masiny niepreryvnowo diejstvija (in Russian), Nauka, Moscow 1969.

[8] A. Czubak, J. Michalczyk, Teoria transportu wibracyjnego (in Polish). Wyd. Pol. Świętokrzyskiej, Kielce 2001.

[9] A. Spivakowski, I. Goncharevich, Vibracjonnyje i volnovyje transportirujuscyje masyny (in Russian), NAUKA, Moskva 1983.

[10] C.A. Krulle, A. Gotzendorfer, R. Grochowski, I. Rehber, M. Rouijaa, P. Walzel, Traffic and Granular Flow'05, ISBN 978-3-54047640-5 Springer Berlin. Heidelberg, New York 2007.

[11] M.D. Sinnott, P.W. Cleary, Granular Matter. 11, 5, 345-364. (2009).

[12] S. Feder, W. Kęska, Z. Kośmicki, Zeszyty Naukowe Politechniki Poznańskiej, Maszyny Robocze i Transport, 57 (2004).

[13] J. Michalczyk, G. Cieplok, Ł. Bednarski, Procesy przejściowe maszyn wibracyjnych i układów wibroizolacji (in Polish). WNT, Warszawa 2010.

[14] J. Michalczyk, P. Czubak, Archives of Metallurgy and Materials 55, 3 (2010). 